\title{
VOZ Y POLIFONÍA EN PASTO VERDE DE PARMÉNIDES GARCÍA SALDAÑA
}

\author{
Voice and polyphony in Green grass (pasto verde) \\ by Parménides García Saldaña
}

Diana Costales García*

\begin{abstract}
RESUMEN
Este artículo se propone demostrar la calidad literaria de la novela Pasto verde de Parménides García Saldaña, la cual ha sido objeto de polémica a lo largo de varias décadas en lo concerniente a su valor artístico, debido a la ruptura que planteó en cuanto al manejo del lenguaje, a la representación sintáctica y tipográfica de la oralidad y al privilegio que otorga al "sentir" sobre el "acontecer", por lo que no hay una "trama" en cuanto tal. Para lograr mi propósito, analizo algunos aspectos de la obra basándome en los conceptos de "voz" y "polifonía" del teórico ruso Mijail Bajtín, así como de la relación entre la técnica literaria y el contexto social y musical de los años 60 en México.
\end{abstract}

Palabras clave: Voz, polifonía, novela, México, años 60.

\begin{abstract}
This article aims to demonstrate the literary quality of the novel Green Grass (Pasto verde) by Parménides García Saldaña, which has been the subject of controversy over several decades with regard to its artistic value, due to the break that raised in regard to the handling of language, the representation and syntactic typesetting of the orality, and the privilege that gives to the "feeling" over the "happening", so there is no a "plot" as soon as such. To do this, I analyze some aspects of the novel, based on the concepts of "voice" and "polyphony "of the Russian theorist Mikhail Bakhtin, as well as the relationship between literary art and social and musical context of the 60's in Mexico.
\end{abstract}

Key Words: Voice, polyphony, novel, Mexico, 60's.

Universidad Iberoamericana, Profesora. México.

Correo electrónico: dianacost@yahoo.com

Recepción: 11/2/14. Aceptación: 12/12/14. 


\section{Introducción}

Durante los años 60 surge en México la llamada "Literatura de la Onda", la cual rompe estructuras en el ámbito literario por sus técnicas innovadoras: la preponderancia de personajes jóvenes, la representación de la oralidad en el discurso escrito, la ruptura con las reglas de puntuación y el hibridismo lingüístico, entre otras. Uno de los escritores de esta generación fue Parménides García Saldaña, y su novela Pasto verde fue recibida contradictoriamente por la crítica en el momento que fue publicada (1968). El texto provoca, hasta la fecha, reacciones maniqueas: hay quienes defienden su estatus de obra de arte, y quienes la atacan de manera despiadada porque no encaja en sus parámetros de "lo literario". Pero ni sus defensores ni sus detractores se dedicaron a realizar una valoración crítica profunda para sustentar su apreciación.

A la luz de algunos fundamentos teóricos del ruso Mijail Bajtín (sus conceptos de "voz" y "polifonía"), haré un análisis de esta novela. En ella, la combinación de ciertos recursos técnicos (representación estilizada de la oralidad como eje central de la obra, léxico juvenil, hibridismo lingüístico (heteroglosia), manejo subversivo de la puntuación, sobreposición de discursos de distintas esferas culturales, contextualización, ironía y ausencia de trama en cuanto tal) constituye una ruptura con la tradición literaria, una propuesta artística y un replanteamiento de lo considerado hasta entonces como Literatura. Asimismo, el manejo de la técnica para dar al discurso una apariencia de espontaneidad reafirma la calidad artística de la obra. A lo largo de este trabajo, me enfocaré en demostrar lo anterior.

\section{La "Literatura de la onda" y su propuesta literaria}

Como sabemos, el texto literario forma parte de un proceso interactivo entre autor, contexto y lector. Los factores histórico-sociales condicionan en su momento la producción del texto, así como su recepción.

En este último aspecto, debemos tener presentes el contexto del autor, el contexto de la obra y el contexto de la lectura: el contexto del autor se integra por la cosmovisión y/o la biografía del mismo, y por los factores histórico-sociales al momento de la creación; el contexto de la obra se constituye por los factores histórico-sociales al momento de ser creada (coinciden con los del autor) y por los de la época y lugar en que se desarrolla el texto (que pueden o no coincidir con los de creación); por último, el contexto de la lectura consiste en los factores histórico-sociales al momento de la publicación (que puede o no coincidir con el de la creación), la competencia del lector (en caso de que el medio en que se desenvuelve sea distinto al de la obra o al del tema), la cosmovisión y experiencia del receptor y la censura.

A modo de antecedente, diremos que la literatura decimonónica (sobre todo de la segunda mitad del siglo) muestra con un "discurso realista-naturalista la incapacidad del individuo de imponer su propia voluntad debido a una serie de circunstancias (sociales y hereditarias) incontrolables para él" (Gunia 121). El llamado "determinismo" era la característica principal de este tipo de narrativa.

Para mediados del siglo $\mathrm{XX}$, se sigue observando en la literatura esta lucha del individuo contra las reglas hipócritas y de aparente decencia que le han sido impuestas por su familia y por la sociedad en que vive, por la tradición y la herencia; finalmente, la sociedad termina imponiendo su voluntad. Un ejemplo de esto es Las buenas conciencias, novela de Carlos Fuentes. Aun así, todavía no encontramos una atención especial hacia los adolescentes, ni una narración desde su perspectiva y con su propio lenguaje.

Hasta alrededor de los años 50, realmente no existía lo que podría llamarse una "cultura de los jóvenes": los niños pasaban a la adultez sin una etapa intermedia. La sociedad consideraba a los individuos de entre 15 y 25 años, "niños grandes" o "adultitos", según iban creciendo o adquiriendo responsabilidades. Cuando el siglo 
llega a esta década, comienza un cambio notorio en esta perspectiva: los jóvenes finalmente toman conciencia de sí mismos como seres distintos a los niños y a los "grandes"; reconocen que viven una edad entre ambos extremos y que cuentan con el derecho de disfrutarla.

La música rock and roll fue el "grito de guerra" y el estandarte del sector juvenil. Paralelamente, comienzan a tener su propio modo de vestir, de hablar, de ser y de pensar.

La literatura, por ende, no puede quedarse atrás en esta "revolución". Comienzan a surgir escritores que abordan la temática juvenil como el centro de su narrativa. En Estados Unidos, los adolescentes leen a Jack Kerouac (autor de la novela On the road -En la ruta-) y a Allen Ginsberg (quien escribió el poema "Howl" - “Aullido"-), entre otros. En México, los escritores jóvenes provienen de una generación que ha nacido y crecido en los medios urbanos; por lo tanto, su literatura refleja estos ambientes y a la gente que se desarrolla en ellos. Dado que son individuos que a sus 17 años nunca se han parado por una granja, no pueden relatar situaciones ubicadas en el campo ni referirse a la Revolución Mexicana y sus consecuencias. Su contexto es el medio urbano de las clases media y alta, que viven la creciente industrialización y americanización de su país, que cuentan con los medios para viajar a Estados Unidos y adquirir sus influencias, y que intelectualmente están en posición de cuestionar las condiciones sociales, económicas y políticas del ámbito que los rodea. Por mencionar sólo a algunos de los escritores de esta generación, citaremos a Gustavo Sáinz, José Agustín y Parménides García Saldaña, autores de Gazapo, La tumba y Pasto verde, respectivamente. Se trata de una ruptura total con el discurso determinista positivista que incluso está presente en varios autores de la primera mitad del siglo XX como Juan Rulfo, Mauricio Magdaleno y José Revueltas.

\section{Contexto social y musical en el que surge Pasto verde}

Los jóvenes de los años 60 no representaban a la mayoría de la población ni al discurso oficial de un sistema establecido por las generaciones anteriores. Por tanto, los personajes y el narrador pertenecen a una minoría rebelde: los jóvenes de clase media alta que cuestionan e interpelan el discurso burgués.

La novela no sólo rompe con la novela de la Revolución Mexicana, sino incluso critica a este momento histórico y sus consecuencias. En esta cita se nos muestra un recurso muy utilizado en la obra: la ironía. Por medio de ella, el protagonista aparenta alabar a los héroes de la Historia mexicana; pero, dado el contexto planteado por la novela, se infiere que en realidad los ataca, denuncia su inutilidad y su "herencia" a las generaciones posteriores:

[...] uno apenas va viendo lo horroroso que a veces es el camino. Sí, para qué seguir consignas, para qué seguir a esta sociedad de gentes que no tienen nada, ¿qué ha hecho esta gente? Gracias por la herencia de este Mexiquito tan revolucionario,gracias Pancho Villa, gracias Zapata, gracias gracias, qué bonita tierra nos dejaron, qué patria tan bella, gracias, todos los mexicanos estamos muy contentos, gracias a ustedes, los pobres de aquí desaparecieron. ¡Viva la Revolución! (García Saldaña 1985: 97-98)

La "revolución” por la que abogan los jóvenes de la generación representada en la novela no es la de 1910, sino la que sigue las ideas socialistas:

AVISO REVOLUCIONARIO

Se solicitan revolucionarios que no sean tibios ni reaccionarios para encauzar marxistaleninistamente la lucha de clases entre obreros y burgueses toda correspondencia será recibida en cualquiera de las sierras de América

Atentamente Epicuro Aris Teo (1985: 101-102)

Por otra parte, Epicuro se desenvuelve en un medio y una época en que la música juvenil emerge como tal, y el rock da muchas de las pautas que seguirá el texto en cuanto a ritmo y sonido. El rock y Pasto verde tienen algo en común, además de representar las inquietudes de los jóvenes: las palabras y las frases a veces se presentan inconexas, por lo que el oyente debe entrar en el juego de lo que escucha para, a partir 
de eso, "reconstruir" un relato. Debe estar atento al sonido (al beat) y a las palabras ${ }^{1}$.

En una sociedad donde el uso de los sentidos para algo que no sea recibir información es considerado como sospechoso, el rock recurre a la pura sensación, al disfrute indiscriminado. Con su intensidad sonora y esas frases pertenecientes a simbologías comunes y complicidades compartidas, lo que el rock crea no es, en definitiva, un mensaje, sino que potencia una atmósfera. (Antolín Rato 1975: 24)

Pasto verde hace lo mismo: sin una trama en cuanto tal, el manejo del lenguaje $\mathrm{y}$, por consiguiente, el efecto sonoro expresan un sentir más que un acontecer. Y así como la naturaleza ecléctica del rock es "confusión" desde la perspectiva de los conservadores, el estilo de la novela de García Saldaña fue calificado de incoherente y sin sentido por muchos críticos literarios de su época.

Durante la segunda mitad de los sesenta, los cantantes y grupos trasladaron la vivencia psicodélica a la música $\mathrm{y}$, como resultado, llegó el "rock ácido". Algunos ejemplos son las canciones "Mr. Tambourine Man"de Bob Dylan, "Magical Mistery Tour", "Yellow Submarine", "Dr. Robert"3"y "Lucy in the Sky with Diamonds" de The Beatles. Con estas canciones glorificaban la experiencia del "buen viaje", sobre todo el que incluía el uso de LSD como liberador de la conciencia. Algunas de las técnicas de este género de rock eran el alto volumen, la guitarra aguda, el sonido electrónico y el crescendo: este último recurso lo utiliza Pasto verde en términos literarios, a través de la tipografía en mayúsculas y la acumulación de frases e ideas:

rodantes palmoteando silbidos gritos flores al escenario Tania proyecta sobre una pantalla sus diapositivas sicodélicas The Word is love El secreto es amor la palabra es amor Necesitas AMAR AMAR AMAR AMAR AMAR NECESITAS AMOR LET'S SPEND THE NIGHT TOGETHER PASEMOS JUNTOS LA NOCHE TE NECESITO NOS NECESITAMOS” (García Saldaña 1985: 37)

Sin embargo, tanto Epicuro como estos músicos están conscientes de que los viajes por sí solos no solucionarán los problemas del mundo, pero al menos sí brindan la posibilidad de evadirse de una realidad hostil.

Podemos decir que, aun sin que las letras de todas las canciones de estos compositores se consideren poesía, ni la Literatura de la Onda se considere música, sí podemos observar un mayor y muy enriquecedor intercambio entre ambas disciplinas. Pasto verde es un claro ejemplo de la relación que se puede establecer entre música y literatura. Ambas, en cuanto elementos y representaciones de la cultura y de su contexto, muestran (ya sea por separado o en interacción) el nexo entre el entorno social y su discurso.

\section{Conceptos de "voz" y "polifonía", según Mijail Bajtín}

Para realizar un análisis adecuado de Pasto verde, tenemos que tomar en cuenta el contexto histórico y social, la ideología mexicana y su relación con ideologías extranjeras, las manifestaciones culturales y populares del momento -como la música y el cine- y la ruptura de los jóvenes con respecto a los paradigmas establecidos por el sistema y el mundo adulto. Todos estos elementos se representan en la novela creando un conjunto polifónico.

De acuerdo con el teórico ruso de principios del siglo XX Mijail Bajtín, el término polifonía se refiere a que es posible reconocer, en una obra literaria, diferentes voces y discursos que interactúan. En realidad, lo que el autor se representa artísticamente es una interacción (e incluso una confrontación) de voces. Para Bajtín, una voz no es sólo un registro lingüístico y sonoro, sino todo un punto de vista que está inserto en una ideología, y que se puede manifestar y representar tanto en el lenguaje oral como en el lenguaje escrito. El analista debe siempre recordar que el autor de una obra literaria es una persona social y hablante; por lo tanto, no puede desligarse de esto durante el proceso creador. El autor puede expresar su punto de vista a través del narrador (como sucede en Pasto verde) o del objeto de su 
narración. Esta voz será entonces una refracción del lenguaje del autor.

La palabra de tal discurso es, en especial, bivocal. Sirve simultáneamente a dos hablantes, y expresa a un tiempo dos intenciones diferentes: la intención directa del héroe hablante, y la refractada del autor. En tal palabra hay dos voces, dos sentidos y dos expresiones. Al mismo tiempo, esas dos voces están relacionadas dialogísticamente entre sí; es como si se conocieran una a otra (de la misma manera se conocen dos réplicas de un diálogo, y se estructuran en ese conocimiento recíproco), como si discutieran una con otra. La palabra bivocal está siempre dialogizada internamente. (Bajtín 1989: 141-142)

El creador se expresa a través de las "voces" de sus personajes; cada una de éstas expresa una perspectiva inserta en una ideología. El espíritu humano individual se revela a través del diálogo, de su relación con el otro. Según Bajtín, hay puntos "culminantes" en los diálogos: salen del argumento para convertirse en una abstracción de la actitud de un individuo hacia su semejante. En la concepción bajtiniana, lo importante no son las ideas por sí mismas, sino su función y relación con otras ideas.

Para Bajtín, la esencia del género novelístico es la organización artística de la interacción de las distintas voces que participan en la lengua, que a su vez está estratificada en dialectos sociales (edades, épocas, generaciones, modas, jerarquías, regiones, etc.). Cada lenguaje es una interpretación del contexto, una cosmovisión, y si esto sucede en la cotidianidad, de ahí pasa a la conciencia del novelista y, por consecuencia, a su obra. "Estudiar la palabra desde su interior, ignorando su orientación hacia fuera, es tan absurdo como estudiar la vivencia psíquica fuera de la realidad hacia la que está orientada y que la ha determinado" (Bajtín 1989: 109).

La especificidad del lenguaje literario radica en que su lenguaje es la unidad de varios lenguajes. La novela es un microcosmos que refleja un macrocosmos plurilingüe. Los puntos de partida para el lenguaje cotidiano y para el literario, son el plurilingüismo real y los medios de orientación preexistentes: ellos determinan la dirección estilística de la palabra.
El lenguaje es fundamentalmente social, y sólo se puede comprender teniendo en cuenta los procesos dialogizados que se relacionan con él. Para Bajtín, el valor lingüístico de la palabra coincide con su valor dialógico. Pero no se refiere a la concepción superficial de "diálogo" (réplica entre dos interlocutores), sino al "dialogismo" presente en un discurso y hasta en un solo enunciado. Cuando el valor lingüístico es dirigido hacia altos niveles de dialogicidad, se transforma en un valor estético. La diferencia básica entre el discurso cognoscitivo y el estético, es que el primero se orienta a convencer al receptor de una idea o conclusión; no tiene la "apertura" ni el grado de "otredad" que posee el segundo. Por lo tanto, el discurso artístico (que después se convertirá en estético) supera al científico porque nos ayuda a comprender aspectos humanos, que de ningún modo pueden abordarse desde un punto de vista monológico. De esta forma, la obra literaria debe abordarse desde una perspectiva dialógica.

\section{Pasto verde de Parménides García Saldaña}

Pasto verde es una novela cuyo protagonista, Epicuro, es un joven de clase media alta, quien ha tenido la oportunidad de estudiar en Estados Unidos y ha regresado hace tiempo. Permeado por las ideas de su época (revolución política, social, sexual, musical, etc.), está completamente en contra del sistema y de las ideas que tienen que ver con la tradición y códigos morales de las generaciones anteriores. No estudia ni trabaja en señal de rebeldía al sistema capitalista y, al mismo tiempo, se reúne con sus amigos, los "rodantes", a drogarse, fundamentalmente con ácido, pastillas y LSD. Cita a personajes de la intelectualidad, como Francis Scott Fitzgerald, Francisco de Quevedo y Villegas, Séneca y los representantes de la Beat Generation, como Jack Kerouac y Allen Ginsberg. Podemos inferir que Epicuro no es el verdadero nombre del protagonista, sino un apodo que, además, está compuesto por 
varios nombres de filósofos y escritores, lo que sugiere las inclinaciones literarias del personaje: "Epicuro Aristipo Quevedo Galdós del Valle Inclán, Duque de Tecalitlán fundador de la filosofía a mí en la vida el tipo cuadrado madres me vale" (García Saldaña 1985: 25). La novela nos presenta el flujo de su pensamiento, que constantemente fluctúa entre la alucinación, el sueño, el deseo, la imaginación y la vivencia. Pero lo que ocurre con Epicuro es el reflejo de lo que ocurre con un amplio sector de la juventud mexicana de aquel entonces.

En el grupo de los jóvenes, encontramos dos tendencias contrapunteándose: los que están "en onda" y los "fresas" (a quienes Epicuro llama "square" = cuadrados). A esta facción pertenecen los padres y el hermano de Epicuro, sus exnovias y las familias de éstas. La "onda" incluye la empatía con los marginados sociales (el proletariado, por ejemplo). Simpatiza con el socialismo, los ateístas, el hippismo, los estupefacientes, los movimientos pacifistas y la liberación sexual. El rango de "fresa" es atribuido a lo burgués, a las costumbres de las clases media y alta, a las instituciones oficiales como el PRI y la Iglesia, al imperialismo de Estados Unidos, a lo convencional, a la decencia y moral conservadoras y a la tradición en cualquier aspecto. Obviamente, el número de personajes jóvenes en la novela es mayor al de los personajes adultos (la generación de sus padres), lo que ya manifiesta el surgimiento de una "cultura joven" que ha alcanzado también al aspecto literario. El "contenido" (siguiendo la terminología de Bajtín) de la novela consiste en la desorientación, soledad y angustia de un joven mexicano de clase media alta a fines de los años 60 , quien busca su salvación personal (a través de la espera de una mujer ideal, las drogas, la música, la literatura y la renovación del lenguaje) frente a un sistema social represivo y oficializado.

\section{La polifonía en Pasto verde}

A partir de la variedad de "voces" podemos inferir las diferentes perspectivas presentes en el contexto de la novela.
Las "voces" de los jóvenes predominan en la novela y aparecen de muy distintas formas, ya sea en vivencias "reales" o mezclándose con sus sueños y alucinaciones, como veremos más adelante.

La "voz" de los adultos está representada en su mayoría por los padres de Epicuro, así como por los de sus amigos. Una de sus manifestaciones se da por medio de los sueños del protagonista. En uno de ellos, los padres de sus compañeros "invaden" el espacio donde los muchachos se reúnen, lo que podría simbolizar la irrupción de la sociedad en el mundo privado del individuo, lo que limita la libertad de éste para ser y actuar como desea.

$\mathrm{Y}$ en la noche estoy soñando: entran al cuarto los papás de mis cuates rodantes. Y se sientan a mi alrededor a tomar té. Puesdentrodepocotendre-mos elprimercontadoryelprimerarquitecto tantosacrificarnosporellos ellos más tarde entenderánnuestrosdesvelos pero yavecómosonlos jóvenes un poco locos cosas de la edad señora no hay que tratarlos a la antigua son otra generación uno les da todo y ya ve cómo pagan ya recapacitarán algún día algún día sabrán valorizar todos nuestros esfuerzos para que sean hombres de bien uno les da educación dinero yo al mío ya le prometí su valiant si entra a la universidad yalnuestrounviajeaeuropasisalebienesteañoyalnues-trolovamosamandara especializarsealosestadosunidoscuandoacabesucarrerayalnuestroleprometimosyalnuestroleprometimosyalnuestroledimosyquebonitanoviatienemihijosivieraquesevelamuchachitatandebuenafamiliabuenafamiliabuenafamiliabuenafamiliiiabuenafamiliaaaaaa... (García Saldaña 1985: 18-19)

El no dejar espacios entre las palabras da al texto un tono de letanía para imitar el tantas veces repetido discurso de los adultos: lleno de frases hechas, lugares comunes y convenciones vacías. Hacia el final del fragmento, la repetición maniática y las vocales alargadas dan la impresión de una plática que se transforma en una acumulación de sonidos tercos y estridentes, que atormentan a Epicuro y transforman su sueño en pesadilla.

El sistema, la educación y las costumbres aceptadas son también una "voz". Epicuro y sus amigos se relacionan con ella para criticarla y confrontarla. La mayoría de las veces, el protagonista finge asumirla para ridiculizarla 
"desde dentro" e ironizarla. La hibridación es uno de los recursos que más utiliza. Ésta consiste en citar indirectamente un discurso ajeno incorporándolo al propio, sin límites explícitos entre uno y otro. En este ejemplo, recrea el discurso de la moralidad oficial y lo combina con sus propias apreciaciones, sin marcar explícitamente la diferencia entre ambos puntos de vista; más bien, ésta se difumina aunque sin desaparecer del todo:

\begin{abstract}
trata de ser buen chico escucha atentamente al maestro el cinco de mayo recita versos no contradigas nada no critiques nada no abandones las consignas si ves que te persigue la tira saca tu credencial del partido revolucionario [...] dale rosas a tu nena poemas a mamá y a la maestra péinate como hombre no uses ajustados los pantalones [...] aprende a saludar aprende a no soñar ve al servicio militar aunque sepas que contra nada tienes que pelear estudia toda la vida para que termines en una oficina dile a toda la gente que sí es más conveniente un puesto de médico en el seguro que andar de agitador (1985: 78, subrayado mío)
\end{abstract}

Las partes que subrayo son las que dejan ver la opinión del narrador sobre el discurso oficial que imita de los padres, educadores y autoridades. Al contrastar con la mayor parte del mismo, el lector comprende que en realidad está confrontándolo en vez de aceptarlo ciegamente.

En cuanto a las "voces" femeninas, tanto las adultas como las jóvenes están imbuidas por el discurso conservador de la moral tradicional. Las madres enseñan a sus hijas a darse a respetar, defender su virginidad y buscar un "buen partido" para casarse (léase un hombre con buenas posibilidades económicas y muy "decente"). Viven preocupadas por la reputación de la familia y por su imagen moral ante la sociedad. Las jóvenes "absorben" esta mentalidad y tienden a repetir los modelos maternos, a pesar de que muchas de ellas han tenido la oportunidad de estudiar una carrera o de llevar una vida laboral fuera de casa, lo que no hicieron las mujeres de la generación anterior: "Unilingüe en un sillón llora como desesperada, sintiendo su alma destrozada por la pérdida de la decencia de su hermana; mamá, en una silla, está totalmente aniquilada, parece un muñeco de paja" (1985: 126).

Tenemos también la "voz" de los altos círculos intelectuales, que critican negativamente la literatura de los jóvenes como Epicuro y quienes muchas veces apoyan o entorpecen a los escritores por intereses o simpatías más personales que literarias. Conocemos esta "voz" desde la perspectiva del protagonista, quien nos cuenta una escena que quisiera vivir y sólo imagina: tiene una novia que lo ama y apoya en todo, con la cual comenta sus opiniones sobre el tema. En el siguiente fragmento Epicuro no reproduce textualmente el discurso de los autores de suplementos culturales; solamente hace referencia al mismo con sus propias palabras y se posiciona en contra de él. Denuncia en forma sugerente que el éxito en el ámbito cultural está contaminado por los prejuicios de los críticos e intelectuales "reconocidos", las simpatías, la conveniencia y la adulación.

\footnotetext{
-Escucha: joven impertinente siembra el pánico dentro de nuestro máximo círculo intelectual...

-Yo sé quién es el de esa campaña. Ese pinche idiota del sexo amortiguado el saboteador de la revista Always a turd ese güey de Shit un día de estos le voy a partir la madre para que vea cómo aterrorizo a la gente de cagada estoy seguro que es ese pendejo que tiene un grupito de pendejos que a todas horas le están besando las nalgas. Sí, síi, Germán Broca o El Coito Amotinado. Pinche saboteador. Si yo fuera el director de ese pinche suplemento me valdría madres que el idiota ese publicara sus cuentos yo no soy nadie para decir que sus cuentos son buenos o malos yo no le negaría a la gente un cuento suyo no me importa yo simplemente no lo leo y ya pero ese pendejo anduvo saboteando a todo el mundo y un día de estos le voy a poner una bomba en el culo... (1985: 21)
}

Dentro de la ideología machista mexicana (que en los 60 comenzó a verse matizada por la liberación sexual) están presentes varios puntos de vista o "voces". Por un lado está el clásico "don Juan" que utiliza artimañas para seducir a jovencitas. Esto es criticado por Epicuro en una de sus alucinaciones. La "voz" donjuanesca también es vista desde la perspectiva del narrador, quien la presenta a su manera para después expresar su desacuerdo con ella: 
Y estoy viendo a Humpert Trumpet hablando del amor a Lolita Sofisticada la está atrayendo con su madurez con su greña llena de conceptos about the birds n' the bees le está diciendo que él es el único que habla el lenguaje del amor que toda su vida se la ha pasado descifrando El libro del buen amor Que los pájaros y las abejas a él sólo sus secretos han dado but me realmente me enojo me paro de la silla donde estoy sentado y le pico un ojo ya déjese de mamadas -le digo- es mejor que les diga oye nena me gustas a andar con tantos rodeos (1985: 22).

Por otro lado tenemos a Sadito, conocido de Epicuro, quien vive la sexualidad como el típico macho mexicano, quien considera que si un hombre no tiene sexo continuamente, es homosexual. Cuando le narra a Epicuro una anécdota que vivió en compañía de otro amigo suyo, el Conejo, se expresa de él de manera despectiva y prejuiciosa:

-Ayer en la tarde me trepé dos viejas al coche y fuimos al Desierto de los Leones y yo empecé a fajar y el Conejo no atacaba. Y me bajé del coche y lo llamé ¿Sabes de qué se trata, no?

- Sí... sí...

$[\ldots]$

- Entonces ¿por qué estás de pendejo?

- ¿Por qué?

- Mi vieja quiere que me la coja y tú estás de puto

- Es que no todo es sexo, Sadito

- Eres un puto, eso, eres un puto. No me había dado cuenta, eres un puto. Sí, eres puto. Con razón no te coges a Shirley. Sí, ella ha de ser lesbiana. Por eso no cogen... (1985: 111)

Epicuro está en desacuerdo con esta visión. Él es más abierto hacia el tema de la homosexualidad. En los años 60, la postura social oficializada hacia ésta era aún más cerrada e intolerante. Su generación comenzó a "picar piedra" para una mayor aceptación. En respuesta a lo que dice su amigo, él cambia la conversación:

y yo prefiero fugarme y elevarme y no seguir escuchando a Sadito que siempre me viene a contar sus descubrimientos de putos y lesbianas, éste es el caso 24563847. ¿Quién carajos soy yo para criticar a un puto y a una lesbiana?
- A mí esto, Sadito -le digo muy cool-, me vale madres (1985: 111)

También encontramos la "voz" de los políticos mexicanos. Epicuro denuncia la falsedad de éstos en sus discursos de campaña. Esto lo consigue al enfatizar la contradicción entre las buenas intenciones en las promesas hechas al pueblo, y el egocentrismo del candidato a quien sólo le importan sus propios intereses:

os aseguro ser un diputado defensor de los
principios populares, lucharé por vosotros,
queridos campesinos, lucharé para que se vistan
tan a go go como yo, para que vivan en una
residencia como yo, para que traigan un coche
Valiant como yo, les prometo muchas cosas, voten
por mí que soy un extracto popular, os prometo
luchar en la Cámara de Diputados por vuestro
progreso. ¡Viva yo! (1985: 86)

Howl, amigo de Epicuro, comparte con éste y con el resto de los "rodantes" la irreverencia respecto a las instituciones religiosas. De esta forma confrontan, con su "voz", a la "voz" del discurso religioso oficial. Un ejemplo de esto se refiere al dogma católico-guadalupano, responsable de la imagen institucionalizada de la Virgen de Guadalupe: un ser sumiso, dulce y asexuado:

De pronto Howl dice

-Va Juan Diego hecho un pendejo, todo jodido, cargado de mazorcas, y oye una voz que le dice pss, psss y Juan Diego dice ¿qué pasa? Psss, psss insiste la voz y Juan Diego, un poco con miedo, voltea y ve a una gorda, Juan Diego anda hasta el cepillo, alumbradísimo y la gorda le dice, te andaba buscando, no tengas miedo, vengo a salvar a tu pueblo, Juan Diego dice no lo creo, ¿qué pasa? Juan Diego no se da cuenta de los que pasa y al rato cree que está viendo rosas en vez de mazorcas, aún no lo cree y dice ¡qué onda traigo! Pero las rosas ahí están, y luego busca a la gorda y nada y entonces corre a decirle a todo el mundo que vean las rosas, y como todo el pueblo anda hasta el gorro empiezan a correr por las calles ¡Milagro, milagro, milagro! (1985: 121-122)

Aquí podemos ver la desacralización del discurso y simbolismo religiosos. La leyenda (ya oficializada) es trasgredida, lo que implica el rompimiento con el sistema. 
En ocasiones Epicuro asume (más bien simula asumir) la "voz" del discurso religioso para criticarla indirectamente:

Ya las veo devoradas por las serpientes, mujeres deshonestas, os vais a ir al infierno por degeneradas, ved cómo andáis vestidas, locas, maniáticas, cuasipluscuamprostitutas, mujeres de la calle, airadas, airadas, descaradas, bola de corrompidas -señalando a todas las nenas estoy lleno de ira, mis ojos las escupen- os condenaréis si atentáis contra el Movimiento Familiar. (1985: 34)

Todos los personajes y voces están subordinados al narrador en primera persona (Epicuro), quien "absorbe" al resto y nos lo refracta desde su perspectiva. Por esto, no podemos dar a su palabra un voto de fe absoluta; pero al ser él quien dirige la narración, sí debemos concederle un amplio rango de confianza para introducirnos de lleno en la obra. A pesar de que el protagonista nos hace llegar las voces de acuerdo con su percepción, distinguimos claramente las discrepancias entre ellas, así como la semejanza o confrontación que poseen con la voz narrativa.

Además de todas estas "voces", hay dos que no podemos olvidar: la "voz" (tácita) de Parménides García Saldaña, quien las ha manejado a todas al resaltar o minimizar distintos aspectos de ellas, y la nuestra en tanto receptores al momento de la lectura. Nuestra "voz", que definitivamente influirá en nuestra apreciación de la novela, también está sujeta a nuestros contextos espacial y temporal.

Es aquí donde todas las "voces" (incluyendo la filtrada del autor) entran en dialogismo con la nuestra en el momento de la recepción. Obviamente, habrá tantas lecturas como lectores: dependiendo de la apertura del "oyente", de su conocimiento sobre los años sesenta y lo que éstos implicaron a nivel histórico y cultural, así como de su propia experiencia, cosmovisión y ganas de profundizar en lo que lee, variará su grado de identificación o de rechazo.

A partir de toda esta polifonía, vamos refigurando la "historia" que se nos cuenta: con esta palabra nos referimos, más que a una trama en cuanto tal, a una serie de emociones, sucesos y actitudes en interacción. Asimismo, es a través de las estrategias técnicas empleadas para representar la relación interdependiente de las "voces", que se configura la intencionalidad estética (la ruptura con una forma tradicional de hacer literatura) y ética (el cuestionamiento de todo un sistema de valores anquilosados) que presenta la novela. Nosotros como lectores podemos inferir toda esta propuesta a partir de la confrontación polifónica, que incluye no sólo a los registros lingüísticos o a los diálogos puros, sino también a las actitudes y acciones que dan cuerpo y solidez a las "voces" presentes en la obra y, por ende, a la obra misma.

La novela no sólo rompe con la novela de la Revolución Mexicana, sino incluso critica a este momento histórico y sus consecuencias. En esta cita se nos muestra un recurso muy utilizado en la obra: la ironía. Por medio de ella, el protagonista aparenta alabar a los héroes de la Historia mexicana; pero, dado el contexto planteado por la novela, se infiere que en realidad los ataca, denuncia su inutilidad y su "herencia" a las generaciones posteriores:

[...] uno apenas va viendo lo horroroso que a veces es el camino. Sí, para qué seguir consignas, para qué seguir a esta sociedad de gentes que no tienen nada, ¿qué ha hecho esta gente? Gracias por la herencia de este Mexiquito tan revolucionario,gracias Pancho Villa, gracias Zapata, gracias gracias, qué bonita tierra nos dejaron, qué patria tan bella, gracias, todos los mexicanos estamos muy contentos, gracias a ustedes, los pobres de aquí desaparecieron. ¡Viva la Revolución! (García Saldaña 1985: 97-98)

La "revolución" por la que abogan los jóvenes de la generación representada en la novela no es la de 1910, sino la que sigue las ideas socialistas:

AVISO REVOLUCIONARIO

Se solicitan revolucionarios que no sean tibios ni reaccionarios para encauzar marxistaleninistamente la lucha de clases entre obreros y burgueses toda correspondencia será recibida en cualquiera de las sierras de América

Atentamente Epicuro Aris Teo (1985: 101-102) 
Por otra parte, Epicuro se desenvuelve en un medio y una época en que la música juvenil emerge como tal, y el rock da muchas de las pautas que seguirá el texto en cuanto a ritmo y sonido. El rock y Pasto verde tienen algo en común, además de representar las inquietudes de los jóvenes: las palabras y las frases a veces se presentan inconexas, por lo que el oyente debe entrar en el juego de lo que escucha para, a partir de eso, "reconstruir" un relato. Debe estar atento al sonido (al beat) y a las palabras ${ }^{1}$.

\begin{abstract}
En una sociedad donde el uso de los sentidos para algo que no sea recibir información es considerado como sospechoso, el rock recurre a la pura sensación, al disfrute indiscriminado. Con su intensidad sonora y esas frases pertenecientes a simbologías comunes y complicidades compartidas, lo que el rock crea no es, en definitiva, un mensaje, sino que potencia una atmósfera. (Antolín Rato 1975: 24)
\end{abstract}

Pasto verde hace lo mismo: sin una trama en cuanto tal, el manejo del lenguaje $y$, por consiguiente, el efecto sonoro expresan un sentir más que un acontecer. Y así como la naturaleza ecléctica del rock es "confusión" desde la perspectiva de los conservadores, el estilo de la novela de García Saldaña fue calificado de incoherente y sin sentido por muchos críticos literarios de su época.

Durante la segunda mitad de los sesenta, los cantantes y grupos trasladaron la vivencia psicodélica a la música y, como resultado, llegó el "rock ácido". Algunos ejemplos son las canciones "Mr. Tambourine Man²"de Bob Dylan, "Magical Mistery Tour", "Yellow Submarine", "Dr. Robert" "y "Lucy in the Sky with Diamonds" de The Beatles. Con estas canciones glorificaban la experiencia del "buen viaje", sobre todo el que incluía el uso de LSD como liberador de la conciencia. Algunas de las técnicas de este género de rock eran el alto volumen, la guitarra aguda, el sonido electrónico y el crescendo: este último recurso lo utiliza Pasto verde en términos literarios, a través de la tipografía en mayúsculas y la acumulación de frases e ideas:

rodantes palmoteando silbidos gritos flores al escenario Tania proyecta sobre una pantalla sus diapositivas sicodélicas The Word is love El secreto es amor la palabra es amor Necesitas AMAR
AMAR AMAR AMAR AMAR NECESITAS AMOR LET'S SPEND THE NIGHT TOGETHER PASEMOS JUNTOS LA NOCHE TE NECESITO NOS NECESITAMOS" (García Saldaña 1985: 37)

Sin embargo, tanto Epicuro como estos músicos están conscientes de que los viajes por sí solos no solucionarán los problemas del mundo, pero al menos sí brindan la posibilidad de evadirse de una realidad hostil.

Podemos decir que, aun sin que las letras de todas las canciones de estos compositores se consideren poesía, ni la Literatura de la Onda se considere música, sí podemos observar un mayor y muy enriquecedor intercambio entre ambas disciplinas. Pasto verde es un claro ejemplo de la relación que se puede establecer entre música y literatura. Ambas, en cuanto elementos y representaciones de la cultura y de su contexto, muestran (ya sea por separado o en interacción) el nexo entre el entorno social y su discurso.

\section{Estrategias lingüísticas}

Las estrategias lingüísticas por las cuales se da la polifonía, se enfocan en tres aspectos: a) fonética, b) léxico y c) sintaxis ${ }^{4}$. Al surgir lo que llamamos "cultura juvenil", obviamente surge un nuevo hombre que desea hacer oír su (también nuevo) punto de vista sobre el mundo; esta perspectiva se proyecta a través de su uso de la lengua. Este "nuevo discurso" se proyecta a través de dichas estrategias. En el caso de Pasto verde, Epicuro (guiado por la conciencia dominante del autor) utiliza el lenguaje de su entorno espacial y temporal para expresar su cosmovisión. Nuestro trabajo es, a través del análisis, encontrar el orden que subyace en el aparente caos de la novela.

\subsection{Fonética}

A pesar de que Epicuro, en repetidas ocasiones, hace referencia a que está escribiendo sus vivencias -"aquí estoy escribiendo esto" (García Saldaña 1985: 29); "claro que con su presencia bastó para esa tarde triunfar a pasto -cada vez que esta palabra escribo palabra de honor que me alucino-" (1985: 31), se acerca 
mucho a los elementos del lenguaje oral y del ritmo musical, haciendo énfasis en el aspecto sonoro del idioma. La oralidad (que nos remite directamente a la fonética) permite escuchar mejor la lengua, ya que es en ella donde se manifiesta de manera más inmediata su aspecto vivo, abierto y cambiante. Por lo tanto, en esta novela funge como un recurso, como una estrategia para resaltar esta faceta del idioma y para romper con la preceptiva literaria tradicional.

La forma en que el protagonista maneja el lenguaje rompe con la normatividad y preceptiva tradicionales de la escritura. Nos acerca a la experiencia de vivir la lengua, más que sólo usarla bajo reglas estrictas. La representación del lenguaje oral como eje de la obra fue un recurso nuevo en ese momento, un logro del estilo y la poética de Parménides García Saldaña. La forma en que éste, a través de su narrador, nos remite al aspecto de la oralidad es por medio del léxico y de la sintaxis.

Un ejemplo es que, al retratar a las muchachas moralmente conservadoras, destaca una variante específica: las jóvenes cultas que han tenido acceso a una educación superior. En teoría, estas mujeres están más allá de los prejuicios sociales porque han leído y entrado en contacto con ideologías distintas de las que formaron a sus madres y abuelas. Sin embargo, en la práctica siguen siendo moralinas ya que no pueden desligarse de la mentalidad que las rodea $^{5}$. Epicuro se burla de ellas al tomar su discurso y reproducirlo con variantes que aluden al habla de las inditas de pueblo o de rancho. A todo esto se une la interpelación y crítica del narrador. Esto nos recuerda el recurso de las burlas orales, en que se critica el habla de otra persona por medio de la imitación de la misma:

i mira nena la prosima ves que tengas otro nervous breakdown ya no me hables por teléfono me enferman las que todo sólo por el sexo lo complican yo ya istoy mui libri de prijuicios ia superi mis complejos chaparroprietoburgueses pero pues istoi muy indicisa entre lanzarmi a fundu u nu. Digo... ¿Pero tú piensas? ia lii en francis los cuentus de jeningüi, ya leyí la amanti de laidichatelivoir pero ai dios istaba refueti... (1985: 61)
Epicuro muestra aquí una actitud peyorativa tanto hacia las "fresas" como hacia las mujeres de medios rurales: al igualarlas, proyecta toda una crítica ideológica y cultural.

\subsection{Léxico}

En esta parte nos enfocaremos en la representación de los vocablos (nacionales y extranjeros) y en el argot juvenil.

Es de esperarse que el argot esté presente a lo largo de la obra: "revolufia" en vez de "revolución" (1985: 11); "minas" o "milanesas" en lugar de "mí", etc. -“alguien antes de minas usó estos ruidos" (1985: 11); "Sadito viene a burlarse de milanesas sabe que estoy solo como el tío lolo" (1985: 32); "pues cuando me eché -no es albur sino una palabreja que sustituye a maté- al astado" (1985: 31). Otro ejemplo es lo dicho por Howl: "las pendejas nada quieren, sólo sablearte, que tengas un coche de poca madre, los billetes. Si le caes a pie a una vieja suave ni te pela" (1985: 16).

Así como incluimos, por una u otra razón, dialectos extranjeros en nuestro hablar, la lengua es lo suficientemente flexible como para dar cabida a palabras y expresiones de otros idiomas. En Pasto verde, la lengua que más aparece además del español, es el inglés. Esto se explica dado el contexto histórico, político, social y musical de la época, además de sugerirnos el nivel cultural y económico de Epicuro y sus amigos (clase media alta). En los años 50 y 60 , el inglés era una lengua a la que pocos hispanoamericanos tenían acceso: sólo podían estudiarlo quienes pertenecían a las clases media y alta, por ser las clases instruidas.

Epicuro en ocasiones sólo intercala vocablos ingleses en su narración, lo que resalta el aspecto de la oralidad: esto es algo que hacemos con más frecuencia cuando hablamos que cuando escribimos: "[...] y la nena se va y yo me quedo on the street" (García Saldaña 63); "no están tan out las gringuitas"; “- Chinga a tu madre... what? Como si no supieras hablar 
mexicano" (1985: 14). Otras veces los fragmentos en inglés son mucho más extensos. Esto nos habla de un conocimiento mayor del idioma por parte de Epicuro. La parte que subrayo en esta cita, señala un insulto en el español de México ("chinga a tu madre") traducido literalmente al inglés.

-You must be a phenomena. I'm pretty sure that you are that well you're american you can do ev'rythin' you wanna, you can do this like this, like to introduce in your hole an ass, I mean, how is the feelin'? Well baby bye-bye fuck your mother, mother fucker n'fuck your blondes of shit... (1985:15)

Su dominio del inglés es tal, que incluso representa la fonética de este idioma. En el siguiente fragmento, alude a la niña "cuadrada" con la que inicia la novela. Con juegos de palabras y ausencia de puntuación, une y cambia sentidos, por lo que su apropiación de la lengua (en este caso, la lengua inglesa) va de lo morfológico a lo sintáctico: lo importante está en los sentidos que Epicuro "importa" de la lengua extranjera. El cambio de mayúsculas a minúsculas sugiere un cambio en el tono de voz: del grito al volumen normal, o incluso a uno más bajo.

GET OUT OF THIS PLACE I DUNNO FRENCH I SAID GET OUT IF YA DUNNO WANNA ONE OF MY KICKS GET OUT FRENCH GIRL HOW IS YOUR M'OM THE FRENCH FAT WRITE' N' YOUR FATHE' THE FRENCH FOUNTAIN WRITE'? HOW IS YOUR FRENCH? HOW IS YOUR FRENCH POEM 'BOUT THE SOLITUDE N' ISOLATION N' THAT PHONY N' NURD SHIT HOW IS YOUR PHONE, STILL RINGIN'? HOW'RE YOUR FRENCH FRIES? BUT NEXT TIME STUPID FRENCH GIRL i'm gonna ain't got nothin' to do-a go go to hell finkfreshgirl bye bye sweetheart, honey milk... (1985: 61, subrayado mío.)

Inclusive, él nos dice que estudió una temporada en Estados Unidos por deseo de sus padres: "digo es agradecimiento a mis padres que me obligaron a estudiar ochenta idiomas pa'degrande ser culto (¿contentos papá y mamá?) en agradecimiento a los contribuyentes de mis cervatanas que me mandaron a estudiar a una universidad gabacha" (1985: 12).

\subsection{Sintaxis}

Este aspecto se refiere al orden del discurso, presencia o ausencia de puntuación y tipografía.

El uso del hipérbaton reitera la admiración de Epicuro por los poetas barrocos (Quevedo, Sigüenza y Góngora...) y es una forma de lograr que el lector preste más atención a lo enunciado y concientice su lengua. Además, es muy significativo en tanto que la ruptura del orden convencional da origen a la creación de un nuevo orden. Pero sobre todo, esta alteración en el orden sintáctico es usado por muchas personas en el lenguaje oral para jugar con el idioma y bromear con ella: "me ubico de la compañía grabadora de discos en una sala" (García Saldaña 1985: 11). Por otra parte, quienes también usan el hipérbaton son precisamente los compositores de canciones, ya que este recurso es a veces necesario para crear rima. Esto nos remite a las inclinaciones literarias y musicales del narrador:

\footnotetext{
La gente fresa para comer pollo y pescado usa guantes blancos y para sacar del martini seco las aceitunas usa palillos de plástico y para abrir las portezuelas de sus lujosos extranjeros carros usa el meñique dedo y si te ve caminando pero sin andar trajeado te dice jay Dios qué cosas se ven por estos suelos! (1985: 20)
}

Para externar esta actitud lúdica con el lenguaje, además del hipérbaton está el lenguaje rebuscado (o proveniente de otro dialecto del mismo idioma) que se mezcla con el coloquial: "-Os pido perdón pues a ratos no escucho porque se me va la onda" (1985: 50).

La ausencia de puntuación facilita la polisemia y las lecturas variadas de una misma construcción, como en este ejemplo: "y llego al strip tease a ver a wild thing she's so good n' she knows the show biz biz entro todo desconsolado pero al verla tengo un sueño de grande soy james bond y veo a Made in Suecia haciéndole señas a Wild Thing-a Wild Thing me está dedicando el show claro claro soy Yeimsbombom: from me to you" (1985: 63, subrayado mío). La parte señalada se podría leer: "veo a Made in Suecia haciéndole señas a Wild Thing-a Wild Thing[;] me está dedicando el show", o bien: "veo a Made in 
Suecia haciéndole señas a Wild Thing-a[.] Wild Thing me está dedicando el show": depende del sitio en que hagamos la pausa al momento de leer. Lo que hace en la palabra "Yeimsbombom" es transcribir "James Bond" tal como se pronuncia, unirla en un solo vocablo y combinar este último con la palabra "bombón", que alude a un buen aspecto físico. Esto nos recuerda una vez más la flexibilidad del idioma, quien puede adaptarse sin problemas a la improvisación e ingenio del hablante.

En muchos fragmentos de la obra, la repetición de enunciados y las palabras que riman producen un ritmo musical, lo que sugiere el gusto del narrador por la literatura y por las canciones. Desde el inicio encontramos énfasis en la palabra "nena", que si bien no es muy usada en la cotidianidad, sí lo era en las canciones de rock y baladas de ese entonces. Esto es una forma de acercar su relato al ámbito de la música del momento. Otros elementos que nos remiten a esto son las interjecciones usadas en las composiciones en inglés (Yeah!, Oh!...) y expresiones de la canción cubana (¡Sabor ahí!): "nena le digo deja ya las pendejadas a un lado[...] y veo que de mi balcón una nena parecida a ti se va cayendo sabiendo que es la nada nena dejemos a un lado las pendejadas y aprendamos a vivir ¡Sabor ahí! Yeah!” (1985: 116). Hay veces en que Epicuro casi anuncia explícitamente que desea acercar la expresión literaria al ritmo de una canción: "(this must be my farewell song to the strawberry girl que en cosas de amor siempre hace una enajenación... All right)" (1985: 20).

Por otra parte, en algunas ocasiones el cambio de la alucinación a la realidad tampoco tiene introducción explicatoria. El lector infiere que ha habido una transición al ámbito de lo real gracias al contexto construido verbalmente por Epicuro:

[...] estoy en el coche de Sadito vamos los que ruedan por el Paseo de la Reforma oyendo Well I told you once and I told you twice But ya' never listen to my advice $[. .$.

[...] las nenas bailan, los cuates reparten flores a los adultos que se bajan de sus coches y contemplan el ESPECTÁCULOANTIFRESA MAKE LOVE NOT WAR... Oigo Radiocentro ¿quién le cambió? Clic.
Me sacaron de mi onda les digo. Perdón maese. ¡Qué onda! Pero qué onda (1985: 69-70)

Otras veces los cambios están señalados por frases como "y de pronto" (1985: 72), "la alucinación se va" (1985: 69), "y despierto del sueño" (1985: 73).

Epicuro, además de escuchar las canciones que están de moda en su momento y de identificarse con ellas, las intercala en su discurso y las hace parte de él (ya sea transcribiéndolas literalmente, traduciéndolas al español o recreándolas para transformar su sentido) de la misma forma que las hace parte de su vida: "Pero entre los botones nena vamos a pasar la noche juntos (oh oh oh oh acabo de fusilar una frase de los Rolling Stones oh oh oh $\mathrm{oh}^{7}$ )" (1985: 20); "Chao, chao my strawberry girl forever ${ }^{8}$ !” (1985: 121); “oh i'm cryin' where yeah yeah la música de violines se hace más pero más triste yeah yeah she loves you she loves you who who who who oh oh oh oh" (1985: 62).

La "hibridación" es el recurso más utilizado por el autor a través de Epicuro. En un fragmento que inicia con la "voz" de otro personaje, de repente pasa a la "voz" del protagonista sin pausas ni advertencias de ningún tipo:

-Sobrino pero yo a mi amante la quería como un
hombre ama a una hembra pero las mujeres son
como las copas vacías que en ellas pusimos un
poco de néctar en esta vida si eres un romántico
empedernido te lleva la chingada sobrino recuerda
este consejo que te dice tu tío que fue tercera voz de
un trío en los tiempos heroicos de vino mujeres y al
tiro... pues de tantas mujeres que tuve ya se me fue la
onda de lo que mi tío me estaba contando (1985: 26)

Epicuro es dado a mezclar, en una misma construcción, no sólo distintas "voces" sino también distintas intenciones en una sola de ellas. En este fragmento podemos observar claramente cómo va de la idealización de la figura femenina (que heredamos del Romanticismo) a la irreverencia total sin ninguna puntuación de por medio: "Mujer divina ${ }^{10}$ que hueles a fragancia de flor de calabaza y taquitos de panza mujer arrobo yo sin ti no soy nada y te entrego mi vida anonadada mujer fatal y adorada ${ }^{11}$ y a tu cuerpo vivo esclavizado por tarado y yo mujer adorada 
te entregué mi alma amada y me la dejaste absolutamente defecada oh mujer idolatrada tu cuerpo en flor me tiene desarrapado [...], no cabe duda que de la canción romántica soy el amo" (1985: 26-27). Esta actitud irreverente, así como la forma de pensar del protagonista sobre el concepto de la mujer virginal, nos dice que no está de acuerdo con la visión del bolero acerca de la figura femenina.

Según lo que se trate de expresar, serán los medios elegidos para ello, aunque eso implique transgredir los estilos y las técnicas consideradas hasta entonces como artísticas, o incluso, transgredir el lenguaje mismo.

La recreación lingüística que se encuentra aquí es la del lenguaje de los jóvenes mexicanos (que en los años 60 no eran aún mayoría) que se han ido a estudiar a los Estados Unidos y han regresado a combinar lo aprendido en ese país con lo propio; esto se aplica en lo lingüístico, ideológico, cultural, etc. Podemos ver una línea de fuga que atraviesa al castellano influenciado por el inglés; pero en ocasiones, en el lenguaje de Epicuro ocurre también a la inversa: el inglés que Epicuro domina se ve también atravesado por su lengua materna, el español, creándose de esta forma un hibridismo lingüístico.

\section{Conclusión}

Parménides García Saldaña logra proponer, en Pasto verde, toda una "poética" nueva, sostenida por varias características interdependientes: a través de su protagonista $\mathrm{y}$ narrador (quien se encuentra de forma permanente entre la alucinación, el recuerdo, el sueño, la imaginación y la vivencia), el autor representa "voces" o "hablas" en todas sus tesituras: semántica, fonética, sintáctica y morfosintáctica, lo que da lugar a un dialogismo fácilmente reconocible. Todas estas "voces" (a decir de Bajtín, quien usa el término para definir los diferentes puntos de vista sobre un objeto o situación, manifestados a través del habla y de las acciones) se interrumpen constantemente constituyendo una forma de "polifonía". Esto se adecua al pensamiento bajtiniano de que la palabra es dialógica, pero no sólo en el enfrentamiento de voces: la palabra misma ya tiene cargas semánticas de muchos hablantes. La interacción y confrontación de "hablas" nos permite reconocer o inferir varios elementos del contexto histórico, así como las actitudes del protagonista, de los jóvenes, de los adultos y del sistema oficializado. A partir de estas "voces", el lector puede "reconstruir" la realidad representada; pero no como una trama en cuanto tal, sino como un cúmulo de experiencias, ideas, emociones, anhelos y "viajes" inducidos por el ácido. A través de la "voz" de Epicuro (quien presenta a las "voces" de los demás personajes e instancias desde su perspectiva), se dan los elementos de una ruptura en dos vertientes: la estética y la ética.

La ruptura estética tiene como eje principal la representación de la oralidad como recurso fundamental de la obra. La oralidad permite "escuchar" mejor la lengua; y al escribir como se habla, se le convierte en parte de la experiencia narrada: se vive y no sólo se utiliza para transmitir un acontecimiento. Al plasmarla en un texto literario, al derribar la frontera entre "lengua oral" y "lengua escrita", García Saldaña consigue que se concientice aun más este aspecto del idioma. En Pasto verde, la oralidad se "oye": se inclina y llama la atención hacia la espontaneidad de lo cotidiano.

La ruptura ética se da con respecto a los valores anquilosados de una sociedad burguesa, hipócrita y conservadora, así como a los aspectos políticos y económicos: se critica al sistema capitalista y se entrevé que el narrador simpatiza con el comunismo, por considerarlo una mejor opción. Esto alude también a los cambios que se daban en ese entonces en dichas áreas. A la ruptura estética se une la protesta, la ruptura con las generaciones precedentes y con la rígida moral imperante hasta entonces.

Como ya he mencionado, debido a la drogadicción del protagonista (y a que las técnicas de la obra apuntan hacia la representación del estado alterado de conciencia), pareciera que Pasto verde no tiene orden ni lógica ya que todo aparece entremezclado. Sin embargo, reconocemos como constantes la soledad, la 
frustración y la desesperación del personaje; su búsqueda de liberación personal a través de un lenguaje nuevo, de la música, de las drogas y del amor de una "mujer ideal" (distinta a la mujer convencional) que él espera llegue pronto a su vida. Asimismo, en medio de los episodios alucinógenos, el narrador es lo suficientemente lúcido como para filosofar y cuestionar las estructuras del sistema cultural de su momento, así como para proponer su propia visión, lo que hace de él un "rebelde con causa". Por otra parte, el título de la novela es doblemente significativo: "Pasto verde", además de aludir a los estupefacientes, es el símbolo del paraíso personal de Epicuro y de la salvación que tanto anhela; es una referencia a que el eje de la obra será precisamente la búsqueda de esa liberación individual. Todos estos elementos nos remiten a conciencia e intencionalidad: a una obra pensada y configurada bajo una coherencia narrativa y una lógica distintas a las tradicionales. Con esto, se le da al lector una participación todavía más activa, al hacerlo esforzarse para encontrar el orden oculto en el aparente caos.

Esta nueva forma de arte (que en Pasto verde aparece muy bien lograda), al no estar ligada a una preceptiva establecida, plantea la necesidad de aproximarnos a ella con una óptica igualmente nueva y abierta. Debemos enfrentarnos a la obra con la conciencia de que estamos ante la manifestación de una nueva cosmovisión, expresada por medio de una nueva "voz" o "habla": la del nuevo joven.

\section{Notas}

1. Esta cercanía entre literatura beat y música rock es una de las razones por las que el protagonista de Pasto verde idolatra y sigue a estos músicos tanto como a los poetas Kerouac y Ginsberg.

2. En su sentido literal, "tambourine man" es el hombre que toca el pandero. En el argot de los drogadictos estadounidenses (al menos los de ese momento), es el vendedor de yerba.

3. El "Doctor Robert" era quien le conseguía las drogas a John Lennon.
4. Por supuesto, estos tres aspectos son interdependientes y se complementan unos a otros, por lo que su separación en este análisis obedece únicamente a motivos prácticos.

5. Estos personajes son el reflejo de la sociedad en que aparece Parménides García Saldaña: una sociedad que aparentemente rompe con la tradición, pero que en el fondo permanece anclada a sus moldes anteriores. De ahí el rechazo de este sistema hacia un hombre como él (y como Epicuro), que se rebela y "adelanta" a su época.

6. Su inclinación hacia la música cubana obedece a que, además de sentirse atraído por sus ritmos, simpatiza con la ideología comunista.

7. La frase es de la canción "Let's spend the nigth together" ("Vamos a pasar la noche juntos") de The Rolling Stones.

8. La canción original de The Beatles dice "strawberry fields forever". El cambio de "fields" (campos) por "girl" (chica) cambia el sentido de la frase para convertirse en una crítica a las chicas "fresas". Tanto esta nota como la número 9 ejemplifican la integración y refiguración de la música de moda en la configuración de la novela, otorgando un nuevo sentido a los referentes populares del contexto.

9. "I'm crying" es una canción de The Animals y la frase también está incluida en "I'm the walrus" de The Beatles. "She loves you" es otra canción del mismo grupo.

10. "Mujer divina" alude a la canción "Mujer" de Agustín Lara. El bolero es una de las manifestaciones más claras de la herencia cultural del Romanticismo del siglo XIX: la idealización hacia la figura femenina. Este fragmento puede constituir también una crítica indirecta hacia este género musical.

11. La idea de la mujer en el Romanticismo es maniquea: o es pura y casta, o lasciva y maliciosa. Pero en cualquier caso posee una extraordinaria belleza física.

\section{Bibliografía}

Alvarado, Ramón y Lauro Zavala. (comp.). 1993. Diálogos y fronteras. El pensamiento de 
Bajtín en el mundo contemporáneo. Nueva Imagen. México: Benemérita Universidad Autónoma de Puebla-UAM-Patria.

Antolín Rato, Mariano. 1975. Bob Dylan, 2. Madrid: Jucar.

Bajtín, Mijail. 1989. Teoría y estética de la novela [1975]. trad. Helena Kriukova y Vicente Cazcarra. Madrid: Taurus.

Bubnova, Tatiana. 2004. "Introducción a Mijail Bajtín”. Seminario Permanente de Investigación. CITRU-UNAM-Universidad Iberoamericana. Ciudad de México.

Costales García, Diana. 1999. Relámpagos irónicos sobre la Revolución del 29: estrategias narrativas desmitificadoras de la historia mexicana en Los relámpagos de agosto de Jorge Ibargüengoitia. Tesis de Licenciatura. México: Universidad Iberoamericana.

Costales García, Diana. 2009. Entre la tradición y la onda. Un estudio desde la palabra en Pasto verde de Parménides García Saldaña. Tesis de Maestría. México: Universidad Iberoamericana.

García Saldaña, Parménides. 1985. Pasto verde. [1968]. México: Diógenes, $3^{\text {a }}$. ed.

Gunia, Inke. 1994. ¿"Cuál es la onda"? La literatura de la contracultura juvenil en el México de los años sesenta y setenta. Frankfurt am Main: Vervuert. 